\title{
Secrets in fingerprints: clinical ambitions and uncertainty in dermatoglyphics
}

Cite as: CMAJ 2018 May 14;190:E597-9. doi: 10.1503/cmaj.180057

W e usually think of fingerprints as being physical markers that can establish the identity of individuals in criminal investigation or other areas of biometric identification. However, throughout the last century, scientific researchers and clinicians have analyzed the patterning found on fingerprints (as well as palms and soles) for other purposes as well. Much of this work was carried out within the discipline of "dermatoglyphics," a term invented in 1926 by Tulane University anatomists Harold Cummins (18941976) and Charles Midlo to describe the study of ridged skin in physical anthropology and other scientific fields. Fingerprints had been the focus of academic study before this point, of course. Johannes Evangelista Purkinje's (1787-1869) early classification of fingerprints and Francis Galton's (1822-1911) wide-ranging research are often viewed as milestones in the development of this knowledge. ${ }^{1}$ However, it was not until the 20th century that ridged skin patterning became the focus of an actual discipline, one with common methods and data sets and, in the post-World War II period, academic associations. ${ }^{2}$

This article examines the history of one application of dermatoglyphic knowledge: the development of techniques to diagnose Down syndrome (known as "mongolism" earlier in the 20th century). The ambitious idea that dermatoglyphics could reveal the "secrets" of this and other congenital conditions propelled research in the field and encouraged connections among researchers and clinicians. It also eventually revealed the discipline's limitations, a point that would only become clearer amid the late 20th-century shifts in medical genetics that have made chromosomes and, ultimately, DNA the most important objects of investigation.

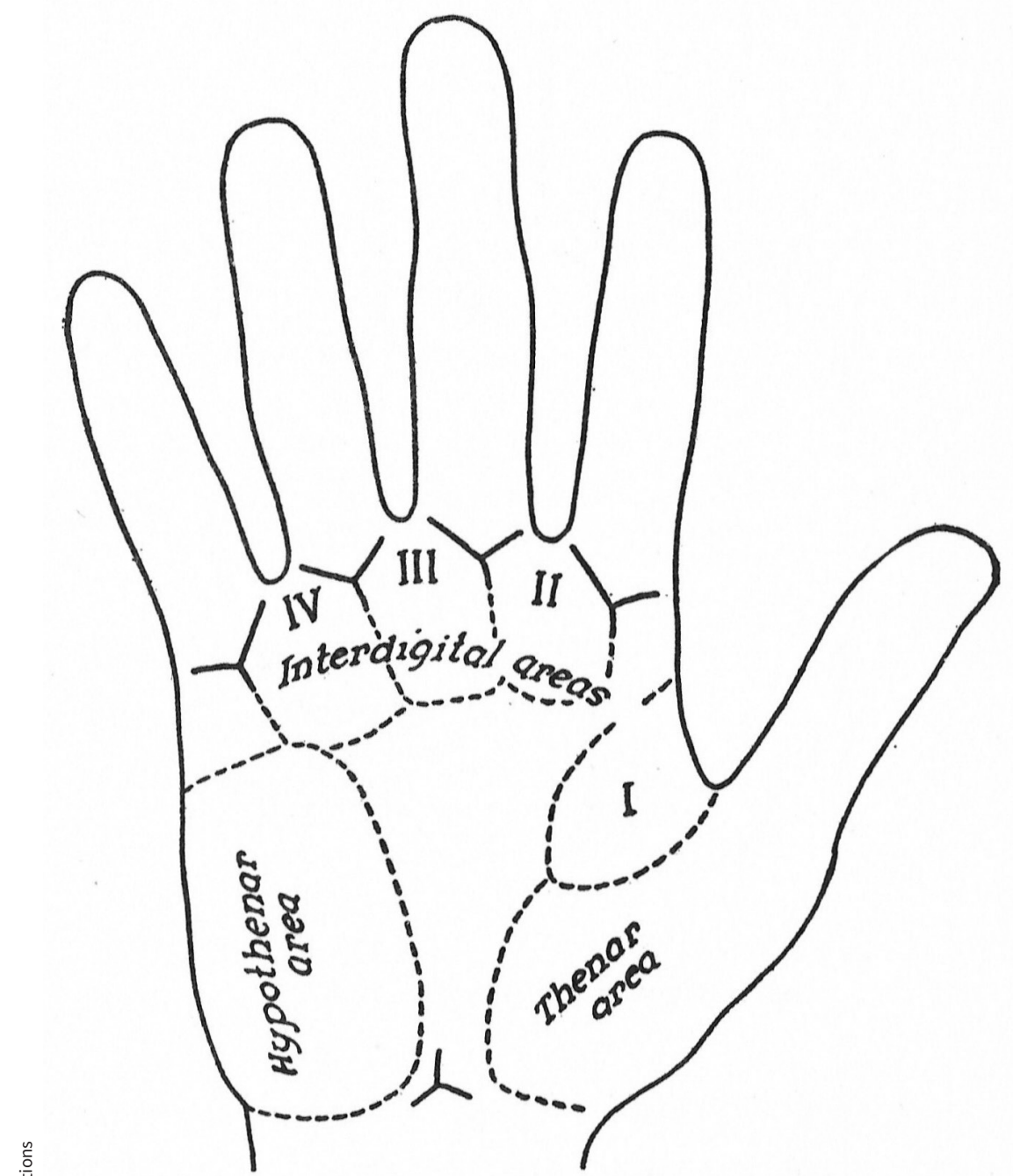

\section{FIG. 59.- Map of the six chief dermatoglyphic areas of the palm.}

Mapping the palm. Used with permission from: Cummins H, Midlo C. Finger prints, palms and soles: an introduction to dermatoglyphics. New York: Dover Publications; 1961:85.

Harold Cummins, who did much to develop the disciplinary identity and methodology of dermatoglyphics, also played a role in defining the early clinical ambitions of this field. In the early 1920s, Cummins was investigating the anatomy and developmental etiology of hyperdactyly and other congenital malformations of the hands and feet, and increasingly came to focus on the friction ridge patterning that presented itself in such cases. $^{3}$ Soon, however, Cummins joined a 
growing network of researchers who were beginning to survey variations in the fingerprint and palm patterning found in different ethnically defined populations. ${ }^{2}$

Such research, which was being conducted in North America, Europe, East Asia and elsewhere, assumed that fingerprint patterning was a partially inherited trait that could be used to investigate genetic relationships between human populations. Influenced by early 20th-century physical anthropology, these researchers also assumed that populations could be divided into anatomically distinct "races" that would manifest distinctive proportions of arches, loops and whorls on their fingerprints. Through these surveys, researchers such as Cummins came to posit that there were certain "normal" or baseline frequencies in the fingerprint and ing of those identified as having mongolism. The presence of a so-called "simian crease" along the palm had been associated with mongolism since the first decade of the 20th century. ${ }^{5}$ Cummins focused, rather, on multiple areas of ridged skin on the palms and fingers, which provided an even greater amount of potentially diagnostically useful information. For example, Cummins observed more ulnar loops on the fingerprints of those who had this condition than would normally be expected, the unexpected appearance of radial loops on the fourth and fifth fingers, and a triradius (the point at which three distinct surfaces of ridged skin converge) located high on the palm. Cummins extrapolated a larger point about the etiology of this condition namely, that the "physical distinctions of

\section{The 1950 s and 1960 s saw rigorous studies of the genetic heritability of fingerprint patterning and even attempts to develop fingerprint-based tests for confirming paternity.}

palm patterning of human populations. This approach naturally raised questions about what it meant when an individual's fingerprints or palm patterns seemed to deviate from these values.

By the mid-1930s, Cummins had turned to the ridged patterning found on palms and fingers of individuals affected by "mongolism." This disease category originated in the racist assumption that reversion to supposedly "Mongolian" racial characteristics caused the intellectual disability and physical signs associated with this condition (mongolism was gradually reconceptualized as Down syndrome or trisomy 21 after confirmation of its chromosomal etiology by Jérôme Lejeune and Marthe Gautier in 1958). 4,5

Cummins documented certain tendencies in the palm and fingerprint pattern- mongolism exist as early as the third and fourth fetal months, the period in which the dermatoglyphics are differentiated in definitive form." 6

Cummins soon collaborated with Ralph Victor Platou (1909-1968), head of Tulane's department of pediatrics, to establish the reliability of dermatoglyphic evidence in the diagnosis of mongolism. Their work culminated in a study of 275 sets of handprints taken from the patients of 82 physicians, who submitted the samples for examination. ${ }^{7}$ The referring physicians' own diagnoses of the patients were compared with the results of Cummins' procedure, which was based solely on examination of ridge patterning on the palm. That these independent diagnoses matched in a high percentage of cases suggested to Cummins and his collaborators that dermatoglyphic examination was a reliable method for diagnosing mongolism, at least relative to the practices then used, which relied on observations of physical appearance.

All of this coincided with a general expansion of interest in dermatoglyphics among scientific researchers. The 1950s and 1960s saw rigorous studies of the genetic heritability of fingerprint patterning and even attempts to develop fingerprint-based tests for confirming paternity. ${ }^{8}$ Researchers also surveyed fingerprint and palm patterning of individuals affected by a range of conditions and diseases, including phenylketonuria, congenital heart disease, schizophrenia, as well as the trisomies and other conditions that were just starting to be identified using chromosomal analysis. ${ }^{9}$ By the early 1960 s, geneticist Irene A. Uchida (1917-2013), a former student of University of Toronto geneticist Norma Ford Walker (1893-1968), was using dermatoglyphic methods to differentiate the newly discovered trisomies 13 and 18 from mongolism. ${ }^{4}$ Given that medically oriented research into chromosomes was still in its early stages and identification of chromosomal disorders involved a degree of ambiguity, dermatoglyphics provided an accepted way of reconciling chromosomal findings with clinical signs.

Dermatoglyphics was also being portrayed as a promising field of scientific research in the press. A Pittsburgh PostGazette profile of Cummins published on July 9, 1959, for example, bore the headline "Secrets in Fingerprints: Prof Develops Dermatoglyphics Which Determine Right, Left-Handedness, Mongoloids and Schizoids." 10 The piece asserted the reliability of dermatoglyphic methods while suggesting that they could be useful for diagnosing schizophrenia. A description of the dermatoglyphics research of Tulane geneticist H. Warner Kloepfer (1913-1982), which was published in The Washington Post on Oct. 11, 1961, noted that, "He can tell whether you have a rare eye disease or a hereditary heart ailment, or if you are a congenial idiot [sic]." The larger point was indicated in the article's title: "Science reads palms for signs of illnesses." 11

Contrary to these claims of efficacy, this was a period in which the clinical limitations of dermatoglyphic analysis were 
becoming more apparent. As had long been recognized, even the patterning observed in conditions such as Down syndrome might fall within the range of normal dermatoglyphic variation and could be found, albeit rarely, on the hands and fingers of unaffected individuals. It also became clear that aside from Down syndrome and, it was soon discovered, trisomies 13 and 18, other conditions did not present dermatoglyphic patterns that were unambiguous or consistent enough to aid in diagnosis. Although examination of the fingerprints and palms of infants, for example, could call attention to "abnormal influences in early gestation," it was an altogether different proposition to claim that such patterning could be used to differentiate between the myriad disorders that might present themselves in a case. ${ }^{12}$

The 1960 s and 1970 s were the pinnacle of interest in dermatoglyphic knowledge but also marked the start of a decline in the activity and status of this discipline. One factor in this shift was resolution of the etiological and diagnostic uncertainties surrounding mongolism that had lent clinical value to dermatoglyphics in earlier decades. More broadly, the rise of human genetics based on molecular biology has meant that attention has shifted to DNA.

The assumption that there might be discoverable secrets in fingerprints provided the impetus for decades of scientific research and clinical application in dermatoglyphics during the 20th century. Although such an idea might appear less compelling today, the ambition of using science to explore pressing questions at the intersection of human identity, heredity and health can still be recognized.

\section{Daniel Asen PhD}

Department of History, Rutgers University-Newark, Newark, NJ

\section{References}

1. Cummins H, Midlo C. Finger prints, palms and soles: an introduction to dermatoglyphics. Philadelphia: The Blakiston Company; 1943.

2. Asen D. 'Dermatoglyphics' and race after the Second World War: the view from East Asia. In: Manning $\mathrm{P}$, Savelli M, editors. Global transformations in the life sciences, 1945-1980. Pittsburgh: University of Pittsburgh Press; 2018.
3. Cummins H. Epidermal-ridge configurations in developmental defects, with particular reference to the ontogenetic factors which condition ridge direction. Am J Anat 1926;38:89-151.

4. Miller FA. Dermatoglyphics and the persistence of 'mongolism': networks of technology, disease and discipline. Soc Stud Sci 2003;33:75-94.

5. Wright D. Down's: the history of a disability. New York: Oxford University Press; 2011.

6. Cummins H. Dermatoglyphic stigmata in mongoloid imbeciles. Anat Rec 1939;73:407-15.

7. Cummins H, Talley C, Platou RV. Palmar dermatoglyphics in mongolism. Pediatrics 1950;5:241-8.

8. Matsukura T. Studies on the inheritance of fingerprints. Med J Osaka Univ 1967;18:227-68.

9. Alter M. Dermatoglyphic analysis as a diagnostic tool. Medicine 1967;46:35-56.

10. Secrets in fingerprints: prof develops dermatoglyphics which determine right, left-handed, mongoloids, and schizoids. Pittsburgh Post-Gazette 1959 July 9.

11. Science read palms for signs of illness. Washington Post 1961 Oct. 11.

12. Achs R, Harper RG, Harrick NJ. Unusual dermatoglyphics associated with major congenital malformations. N Engl J Med 1966;275:1273-8.

This article was solicited and has been peer reviewed.

Competing interests: Daniel Asen has received a grant from the National Science Foundation (Award no. 1654990), which supported the research and writing of this article. No other competing interests were declared. 